\title{
Grade 11 Students' Reflections on their Euclidean Geometry Learning Experiences
}

\author{
Eric Machisi ${ }^{1 *}$ \\ ${ }^{1}$ University of South Africa, SOUTH AFRICA
}

Received 21 October 2020 - Accepted 11 January 2021

\begin{abstract}
The teaching of Euclidean geometry is a matter of serious concern in South Africa. This research, therefore, examined the Euclidean geometry learning experiences of 16 Grade 11 students from four South African secondary schools. Data were obtained using focus group discussions and student diary records. Students who were taught using a Van Hiele theory-based approach reported positive learning experiences in Euclidean geometry, while those who were taught using conventional methods reported negative learning experiences. It was concluded that the Van Hiele theory-based approach seems to meet students' needs better than conventional approaches in learning Euclidean geometry. The use of unconventional teaching approaches such as Van Hiele theory-based instruction in the teaching and learning of Euclidean geometry is therefore recommended. Furthermore, teachers should give students an opportunity to evaluate the teaching approaches used in mathematics classrooms. Student input will help teachers change their teaching methods to suit the needs of the students.
\end{abstract}

Keywords: conventional instruction, Euclidean geometry, students' reflections, Van Hiele theorybased instruction

\section{INTRODUCTION}

Euclidean geometry is a key aspect of high school mathematics curricula in many countries around the world. It prepares students for mathematics, science, engineering and technology professions that are at the heart of a country's economic development. Euclidean geometry sharpens our visual, logical, rational and problem-solving abilities that we all need to live. However, despite many explanations for including Euclidean geometry in secondary school mathematics curricula, the teaching of this mathematical aspect has been characterized by serious pedagogical challenges in many countries including South Africa (Naidoo \& Kapofu, 2020; Ngirishi \& Bansilal, 2019; Tachie, 2020), Malawi (Mwadzaangati, 2015), Namibia (Kanandjebo \& Ngololo, 2017), Nigeria (Adeniji, Ameen, Dambatta, \& Orilonise, 2018), Zimbabwe (Mukamba \& Makamure, 2020), Ghana (Armah, Cofie, \& Okpoti, 2018), America (Oueini, 2019), Saudi Arabia (Al-Khateeb, 2016), Jordan (Tahani, 2016), Japan (Jones, Fujita, \& Kunimune, 2012), and Turkey (Köğce, Aydın, \& Yuldız, 2010).
In South Africa, Euclidean geometry was removed from the mainstream mathematics curriculum in 2006, after a series of poor results in the Grade 12 Mathematics examinations. It was alleged that teachers did not have the required depth of content and pedagogical knowledge to effectively teach Euclidean geometry (Bowie, 2009). In January 2012, South Africa reinstated Euclidean geometry in a new Curriculum and Assessment Policy Statement (CAPS). The decision to bring Euclidean geometry back into the mainstream mathematics curriculum came after numerous studies concluded that university students who had not done Euclidean geometry at high school were weaker in their mathematical skills compared to their counterparts who had a geometry background (see Engelbecht, Harding, \& Phiri, 2010; Mouton, Louw, \& Strydom, 2012; Padayachee, Boshoff, Olivier, \& Harding, 2011; Wolmarans, Smit, Collier-Reed, \& Leather, 2010).

While the return of Euclidean geometry was applauded by South African universities, it brought anxiety for both the educators and the learners (Govender, 2014). South African mathematics educators

(c) 2021 by the authors; licensee Modestum. This article is an open access article distributed under the terms and conditions of the Creative Commons Attribution License (http://creativecommons.org/licenses/by/4.0/).

$\square$ e.machisi@yahoo.com (*Correspondence) 


\section{Contribution to the literature}

- This study explored the impact of Van Hiele theory-based instruction on the learning of Euclidean geometry using QUALITATIVE methods.

- This research shows that Van Hiele theory-based instruction has a positive impact on students' attitudes, self-confidence, feelings and emotions, which all contribute to the student's overall academic performance.

- The findings of this research demonstrate the importance of giving students an opportunity to evaluate the efficacy of teaching approaches used by mathematics teachers at high school level. This was missing in previous studies on the impact of using Van Hiele theory-based instruction in teaching and learning Euclidean geometry.

wonder why Euclidean geometry was brought back into the mainstream mathematics curriculum when the challenges that led to its exclusion in the previous mathematics curriculum have not been fully addressed (Ndlovu, 2013). The situation is aggravated by the fact that some of the educators who are expected to teach Euclidean geometry in the Curriculum and Assessment Policy Statement (CAPS) have no previous contact with the topic (Govender, 2014). In an attempt to address some of the educators' concerns, the South African Department of Basic Education (DBE) rolled out a programme to train educators across all provinces in the country, on the new mathematics content that came with the CAPS. This included Euclidean geometry, Probability and Statistical regression. While the training of educators on the CAPS content has gone a long way in upgrading in-service educators' knowledge of Euclidean geometry, not all of the educators' concerns have been fully addressed (Ndlovu, 2013).

In a follow up survey that explored South African mathematics educators' views on the CAPS training they received in 2012, most educators concurred that the training was inadequate for them to teach Euclidean geometry with confidence (Olivier, 2013, 2014). Of the 150 educators who participated in the survey, 60\% indicated that they were not comfortable with Euclidean geometry (Olivier, 2014). Dube (2016), added that in some instances, the CAPS training facilitators themselves seemed to lack adequate knowledge and skills needed to help educators to improve. From this background, it is clear that there is urgent need to find ways to help teachers improve their teaching of Euclidean geometry in schools.

\section{LITERATURE REVIEW}

Euclidean geometry is the study of plane and solid shapes and their properties based on the theorems and axioms developed by the Greek mathematician Euclid. It involves proving riders using theorems and axioms. A rider is simply a non-routine geometry problem. Proving riders is an abstract process that many students find difficult to understand. Many teachers lack the pedagogical knowledge of how to teach proof and reasoning (Mudaly, 2016), and this is the main reason why many students have difficulties with geometric proofs (Bramlet \& Drake, 2013; Mwadzaangati, 2015).

\section{Conventional Approaches to Teaching Euclidean Theorems and Proofs}

The difficulties of students with geometric proofs are primarily due to the continued use of the traditional teacher-centred approaches (Abdullah \& Zakaria, 2013; Siyepu, 2014). Teachers have the habit of teaching in the same way that they themselves were taught (Keiler, 2018). The dominant approach in many geometry classrooms is that: teachers copy theorems and proofs onto the chalkboard followed by teacher lecture; students in turn, copy theorems and proofs into their notebooks; students memorize theorems and proofs and reproduce them in class exercises, tests and examinations without understanding (De Villiers \& Heideman, 2014). Students are treated as "mere receptors of mathematical facts, principles, formulas and theorems" which are not to be challenged (Armah, Cofie, \& Okpoti, 2018, p. 314). This is the traditional way of teaching Euclidean theorems and proofs.

Teachers who employ the traditional methods do not bother to check whether students have mastered the basic geometry concepts from lower grades. They just move straight into the geometry concepts of the current grade. Students are not given an opportunity to investigate, observe and discover geometry theorems and axioms for themselves. Proofs are presented as rigid and ready-made ideas to be accepted without questions. The teacher and the textbook are the only sources of geometry knowledge and students who fail to understand the explanations presented by these two sources are regarded as unable to learn geometry.

The use of traditional teacher-centred methods in teaching Euclidean geometry was found to be less effective than student-centred methods (see for example, Mensah-Wonkyi \& Adu, 2016; Yilmazer \& Keklikci, 2015). However, despite several reports suggesting that the use of traditional methods is not effective in teaching Euclidean geometry, teachers may continue to use these methods for a number of reasons. In South Africa, there are many teachers in schools who did not do Euclidean geometry at high school, college or university who are 
expected to teach the topic in the CAPS (Govender, 2014). Besides not having adequate knowledge of Euclidean geometry content, the teachers lack the pedagogical content knowledge (PCK) for effective geometry instruction. This explains why in a survey conducted by Olivier (2014), many teachers reported that they were not comfortable with the topic, and that the training they had received was not enough to prepare them for the challenges of the classroom.

Unless these teachers are empowered with alternative methods for teaching Euclidean geometry, they are likely to continue to teach the topic in the conventional way.

\section{Van Hiele Theory-based Approach to Teaching Euclidean Theorems and Proofs}

The Van Hiele theory offers comprehensive guidelines for geometry instruction (see Van Hiele, 1984; Van Hiele-Geldof, 1984). The theory defines the hierarchical levels of progression in learning geometry (visualization, analysis, informal deduction, formal deduction, and rigor), and suggests a sequence of activities for organizing geometry instruction at the various levels to enhance students' understanding of geometry concepts. These are: information, guided orientation, explicitation, free orientation, and integration.

According to the Van Hiele theory, students cannot master level $(n)$ if they have not mastered level $(n-1)$. The Van Hieles use this property to explain why, on the one hand, many teachers fail to reach their students in geometry, and on the other hand, many students struggle to understand geometry concepts. It is because of the mismatch between the level of instruction and the students' current levels of mastery of geometry concepts. By adjusting the level of instruction down to the level of understanding of the students, teachers can actually make Euclidean geometry concepts accessible to the majority of their students.

Many studies have tested the efficacy of Van Hiele theory-based instruction on students' performance in Euclidean geometry using quasi-experiments (see for example, Baiduri, Ismail, \& Sulfiyah, 2020; Mostafa, Javad, \& Reza, 2017; Tahani, 2016; Usman, Yew, \& Saleh, 2019). The apparent convergence of findings from these studies is that Van Hiele theory-based instruction is more effective in improving student achievement in Euclidean geometry compared to traditional methods. Previous research, however, evaluated the efficacy of Van Hiele theory-based instruction on student performance using only quantitative methods (such as pre-test/post-test designs) and statistical analyses. Students have not been given the opportunity to share their thoughts on the proposed educational interventions. Experiments with human beings are different from laboratory experiments with non-living objects. Human beings have thoughts, attitudes, feelings and emotions that have the ability to affect the outcomes of the proposed educational interventions. Therefore, student's voice matters.

A view of the present study is that: students' reflections on their Euclidean geometry learning experiences could provide teachers with valuable insights on what they should do or should avoid in order to meet the needs of their students when teaching Euclidean theorems and proofs in secondary schools.

\section{THEORETICAL FRAMEWORK}

Students' reflections in the context of this study refers to students' views, feelings, and attitudes towards their learning experiences in the mathematics classroom. According to the United Nations Convention on the Rights of the Child (UNCRC), children have a right to express their views and thoughts on matters concerning their lives (Abrahams \& Matthews, 2011). That includes views on what and how they learn in schools. In a democratic society, the right to be heard is a basic human right (Cato, 2018). Research indicates that giving students an opportunity to reflect on their learning experiences has several benefits for education leaders, teachers and the students themselves (Rennie Center for Education Research and Policy, 2019).

Students whose voices are listened to and whose contributions are incorporated into the school curricula, develop a sense of ownership of their learning and development in schools (Department of Education and Training, 2018). They are likely to have high self-efficacy and increased motivation levels (Wang, 2013), which eventually lead to better student achievement (Bonnie \& Lawes, 2016; Dell EMC, 2018). Students are expert observers of teachers, how they teach and what goes on in schools (Busher, 2012). They are in the best position to evaluate educational programmes compared to other stakeholders (Bill \& Giles, 2016). Students can provide valuable information on the strengths and weaknesses, successes and failures of educational initiatives (Rennie Center for Education Research and Policy, 2019). Such information can be used by teachers to review and revise their teaching to suit the interests and needs of the students.

The foregoing ideas form the foundation upon which the present study was grounded. With numerous reports suggesting that the teaching of Euclidean geometry in secondary schools is problematic (see for example, Mukamba \& Makamure, 2020; Naidoo \& Kapofu, 2020; Ngirishi \& Bansilal, 2019; Oueini, 2019; Tachie, 2020), the student voice is pivotal in diagnosing the essence of the problem and finding new approaches to improve the teaching and learning of the topic (Department of Education and Training, 2018). Studies based on quantitative data analysis alone are not enough. Thus, the collection, analysis and interpretation of qualitative 
data is therefore essential to augment quantitative data findings.

\section{THE PURPOSE OF THE STUDY}

This research is a follow up to a quasi-experiment that tested the effect of Van Hiele theory-based instruction on Grade 11 students' geometric proof competencies. Quasi-experiment findings showed that students who were taught using the Van Hiele theorybased approach obtained better geometric proof competencies than students who were taught using traditional approaches (Machisi \& Feza, in press). The purpose of this study is to provide a platform for students who participated in the quasi-experiment to present their views, feelings and attitudes towards Euclidean geometry on the basis of their learning experiences. Student feedback is used to suggest ways to strengthen the teaching and learning of Euclidean theorems and proofs in classrooms where students and teachers have difficulties with geometry.

\section{METHODOLOGY}

The researcher used the qualitative research methodology to elicit students' views, feelings and attitudes towards educators' approaches to teaching Euclidean geometry theorems and proofs in secondary schools.

\section{Participants and Context}

This research is a follow up to a quasi-experiment involving 186 Grade 11 students from four conveniently selected township schools in the Capricorn District of Limpopo province, South Africa. The schools were coded C1, C2, E1 and E2. Schools C1 and C2 from Mankweng township formed the control group whereas the other two schools (E1 \& E2) from Seshego township formed the experimental group. Schools were chosen on the basis of their similarity in enrolment, school infrastructure, past school mathematics performance, location, and socio-economic status of communities surrounding the schools.

Of the 186 Grade 11 students who took part in the quasi-experiment, 16 students volunteered to participate in the follow up study. Nine of these were from the control group schools (3 students from school C1 and 6 students from school C2) and the remaining seven came from the experimental schools (3 students from school E1 and 4 students from school E2). Self-selection, a type of convenience sampling method in which participants volunteer to take part in the study, was used to recruit the students. It was presumed that self-selected participants have a greater commitment and willingness to participate in the study than those recruited by persuasion. White (2006) asserts that selfselected individuals "will be highly motivated and have strong opinions on the topic" (p. 188). Participants were informed that students and schools' actual names will not be used in reporting the research findings. Students' actual names were thus replaced by pseudonyms.

In the quasi-experiment, the control group students were taught by their teachers using their usual approaches whereas the experimental group students were taught by the teacher-researcher using a model of instruction designed based on the Van Hiele theory. The Van Hiele theory-based model of instruction included first assessing students' prior geometry knowledge to determine their current level of geometric understanding. This was followed by remedial lessons to bridge the identified learning gaps, in keeping with the Van Hiele theory which states that students should not be introduced to level $(n)$ if they have not yet mastered level $(n-1)$. Grade 11 Euclidean geometry was then taught following the sequence of teaching and learning activities suggested by the Van Hieles: Information, Guided orientation, Explicitation, Free orientation, and Integration. In the Information phase, students were exposed to a brief history of Euclidean geometry, why it should be taught in secondary schools, and its role in real life. Guided exploration involved exploring theorems and axioms using the Geometer's Sketchpad. Explicitation involved explaining what they had discovered in the guided exploration phase. Free orientation involved applying theorems and axioms to solving non-routine geometry problems with no interference from the teacher. In the Integration phase, students shared their solutions to geometry problems in a whole class discussion. The full details of how the Van Hiele model was implemented in teaching Euclidean theorems and proofs are reported in our manuscript entitled "Van Hiele Theory-Based Instruction and Grade 11 Students' Geometric Proof Competencies" which has been accepted for publication in the Contemporary Mathematics and Science Education journal.

The experimental and control groups were taught the same Euclidean geometry concepts for a period of four weeks. Using a pre-test/post-test design, experimental group students performed significantly better than control group students, after controlling for covariates (see Machisi \& Feza, in press). This study explores these findings further.

\section{Data collection instruments}

Data were collected using diaries and focus group discussions. The diary method was chosen because it captures data at or shortly after the time of occurrence of the event (Woll, 2013) and has less recall errors compared to questionnaires that capture events long after they have occurred (Sheble \& Wildemuth, 2009). In education, students' diaries provide valuable feedback that teachers can use to plan future lessons (Yi, 2008).

A diary guide was developed by the researcher using guidelines from available literature. The first part of the 
diary guide explained the purpose of the diary as suggested by Duke (2012) and Rausch (2014). Second, issues of anonymity and confidentiality were addressed to gain the trust of the participants. Third, clear written instructions were given on the variables of interest that the diarists should write about (Bytheway, 2012; Rausch, 2014) and when the diary entries should be recorded. These included: a description of how the geometry lesson was presented; thoughts, feelings and emotions about the presentation; favourable and unfavourable teaching practices; and a description of own attitude towards learning Euclidean geometry. Providing information on the variables of interest was essential to relieve diarists of the burden of deciding what to include in the diary. There were no restrictions on the amount of information students/diarists could write per each variable of interest. Each diary was a small portable notebook made up of 192 pages. Daily entries were allowed to overflow to the next page when necessary.

While diaries are a valuable data collection tool, they should not be used in isolation (Woll, 2013). Instead, they should be used in conjunction with other data collection methods such as interviews in order to enrich findings or as a form of triangulation (Sheble \& Wildemuth, 2009). For this reason, focus group discussions were used to augment the diary method.

A focus group is a carefully planned discussion, in which a small group of participants are brought together by a trained facilitator to generate qualitative data on a topic of interest. Focus groups are ideal for exploring people's experiences, attitudes, perceptions, beliefs, opinions and ideas on a given topic (Dilshad \& Latif, 2013; Knight, 2012; Pearson \& Vossler, 2016). This was exactly the intention of this research. Such information would help teachers to design, redesign and refine their teaching for better student achievement. Focus groups are also relatively cheap compared to individual interviews and allow the researcher to collect a lot of information in a short period of time (Baral, Uprety, \& Lamichhane, 2016).

A focus group discussion guide was developed by the researcher following the recommendations by Krueger (2002) and Kuhn (2016) of what a typical focus group interview guide should contain. It was made up of the Preliminary Section, the Opening Section, the Question Section, and the Closing Section. The critical part of the discussion guide was the Question Section, which included three categories of time-framed questions: engagement questions, exploration questions, and the closing questions. A preliminary list of ten questions was developed and sent to experts for review. The experts' feedback and comments led to three questions being removed from the list. The remaining seven questions (one for engagement, five for exploration, and one for closing) were then entered into a draft discussion guide. The draft discussion guide was pilot-tested on a sample of students who were not part of the study. This resulted in some questions being revised to enhance clarity. A final draft of the discussion guide was thus developed. The five questions used to explore the variables of interest were:

- What do you think about the way Euclidean geometry and geometry proofs were taught in your mathematics classroom?

- How do you feel about the way Euclidean geometry and geometry proofs were taught in your mathematics classroom?

- What do you like or dislike about the way Euclidean geometry and geometry proofs were taught in your mathematics classroom?

- Can you describe your attitude towards Euclidean geometry and geometry proofs based on your learning experiences?

- What did the teacher do that you think contributed to your attitude towards Euclidean geometry and geometry proofs?

The purpose of the focus group discussion guide was to ensure that all important areas of the study were addressed (Reid \& Mash, 2014). It also helped the focus group moderator to stay on track during discussions.

\section{Data Collection}

Participating students were given diaries at the beginning of the school term to record their thoughts, feelings, attitudes, and reflections on personal observations and learning experiences during Euclidean geometry lessons. Each student received a diary guide which informed them on what and when to record. Students were advised to keep diaries at home and record their reflections after school to avoid interfering with their normal school activities. Students were told not to share their diary entries with other participants to avoid bias in research findings. Students were informed that they were free to contact the researcher at any time to discuss issues regarding diary completion. The researcher also contacted each student daily to remind them to record their learning experiences and reflections. A total of ten diaries were completed and returned to the researcher. Five diaries were from the experimental group participants, and the other five came from the control group participants.Focus group participants were informed of the date, time and venue for the group discussions well in advance. The focus group discussions were held when the Grade 11 mathematics teachers had finished teaching the Euclidean geometry chapter. Four group discussions were held; each focus group was formed by the participating students from each school. A trained moderator was hired to facilitate the group discussions on behalf of the researcher. Focus group discussions were recorded using a digital voice recorder. The discussions lasted between one and half to two hours. 


\section{Data Analysis}

Audio recordings of the focus group discussions were transcribed by the researcher and audited by the moderator. Focus group data were coded using Computer Assisted Qualitative Data Analysis Software (CAQDAS) called MAXQDA (Version 18). MAXQDA is a software package developed by a company called VERBI GmbH, based in Berlin, Germany. The program offers tools for importing documents, coding, categorising text segments, and retrieving the coded segments. Diary records were coded manually using word processor. In the context of this study, coding is a process of identifying information that addresses the variables of interest, and assigning a label (word or phrase) that best describes the information (Bazeley \& Jackson, 2013). The coded data can be a single word, a phrase, a full sentence, a picture, or a whole page of text (Saldana, 2013). Saldana, adds that there is no best way to code qualitative data since variables of interest are context-specific. It is a matter of choosing the right instrument for the right job, a characteristic of the pragmatist paradigm. The qualitative data were categorised using labels showing the variables of interest. These were: views and thoughts, feelings and emotions, favourable and unfavourable teaching practices, and attitudes.

Several measures were taken to enhance trustworthiness of the qualitative research findings. Hiring an outsider to facilitate focus group discussions helped to avoid the presence of the researcher biasing students' responses. The selected facilitator entered the research field a month before the focus group discussions were held to establish rapport with the students. Prolonged engagement in the research site helps to gain the trust of the participants (Anney, 2014). As rapport increases, informants are more likely to disclose sensitive information and give honest responses (Sun, 2014). The use of two data collection methods to collect data on the same phenomenon helped to enhance the credibility of findings of the study. The confirmability of focus group discussion and diary findings was enhanced by asking participants to check whether research findings accurately reflected the views they provided (see Holloway \& Wheeler, 2010; Thomas \& Magilvy, 2011). In reporting results, direct quotations from student diaries and transcribed text were included "to show a connection between the data and the results" (Elo, Kääriäinen, Kanste, Pölkki, Utriainen, \& Kyngäs, 2014, p. 6).

The study was granted ethical clearance by the University of South Africa College of Science, Engineering and Technology's Research and Ethics Committee. The study was also approved by the Limpopo Department of Education. Further permission was sought from the principals and school governing bodies of the targeted schools. The purpose of the study and the research activities were clearly explained in the letters addressed to the principals, school governing bodies, parents and students of the participating schools. Schools principals, parents and students signed consent forms to indicate that they voluntarily agreed to take part in the study.

\section{FINDINGS AND DISCUSSION}

In this section, qualitative data from students' diary entries and focus group discussions is presented and discussed. The presentation is divided into three parts. Part A presents data from students' diaries. Part B presents data from focus group discussions. Part C highlights the main ideas emerging from the discussion.

\section{Part A: Students' Diary Records}

A lot of information was recorded in the diaries. However, not every piece of information is worthy to cite and analyse here. Only segments containing the most important textual data will be extracted and analysed in this section.

\section{Diary reports on lesson presentation}

Control group students evaluated the way in which Euclidean geometry theorems and proofs were presented in their mathematics classes using words such as 'fast', 'bad', 'not presented very well', 'confusing', 'not good', and 'hard'. The extracts in Figure 1 attest.

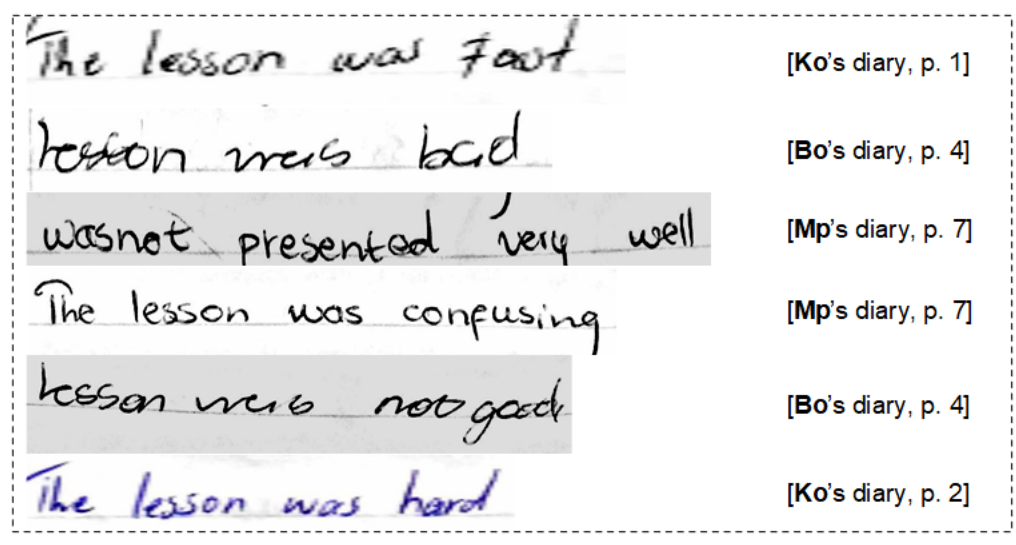

Figure 1. Control group students' lesson evaluations 


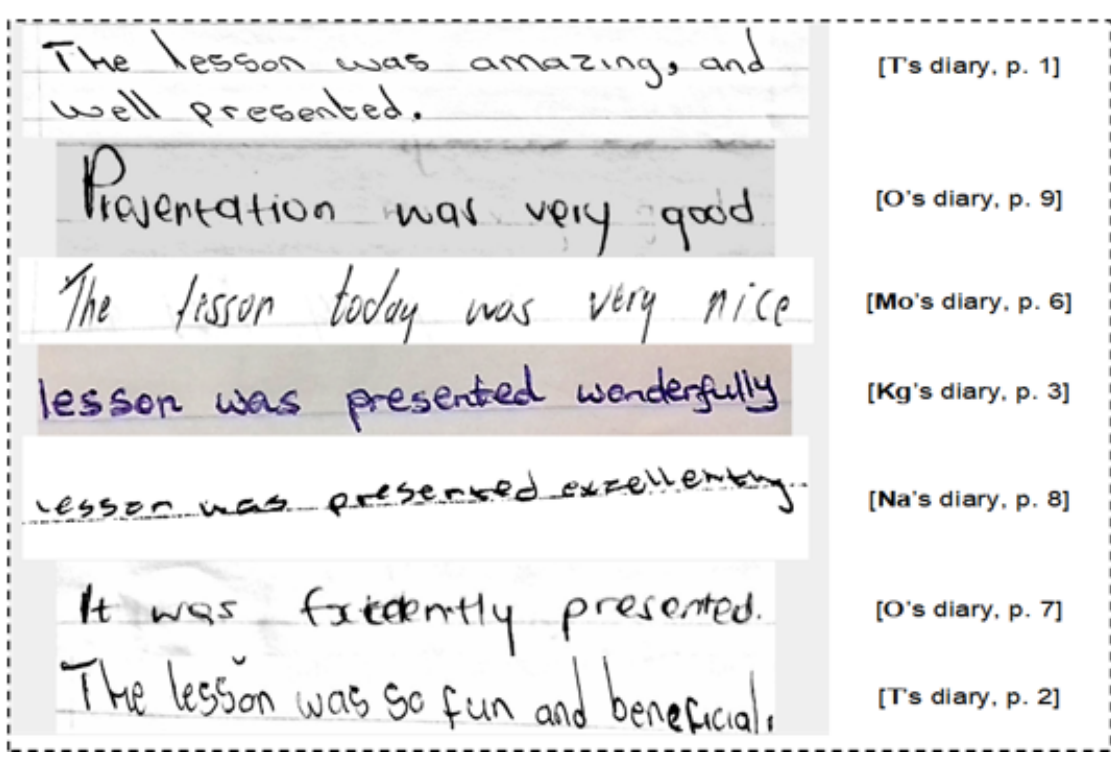

Figure 2. Experimental group students' lesson evaluations

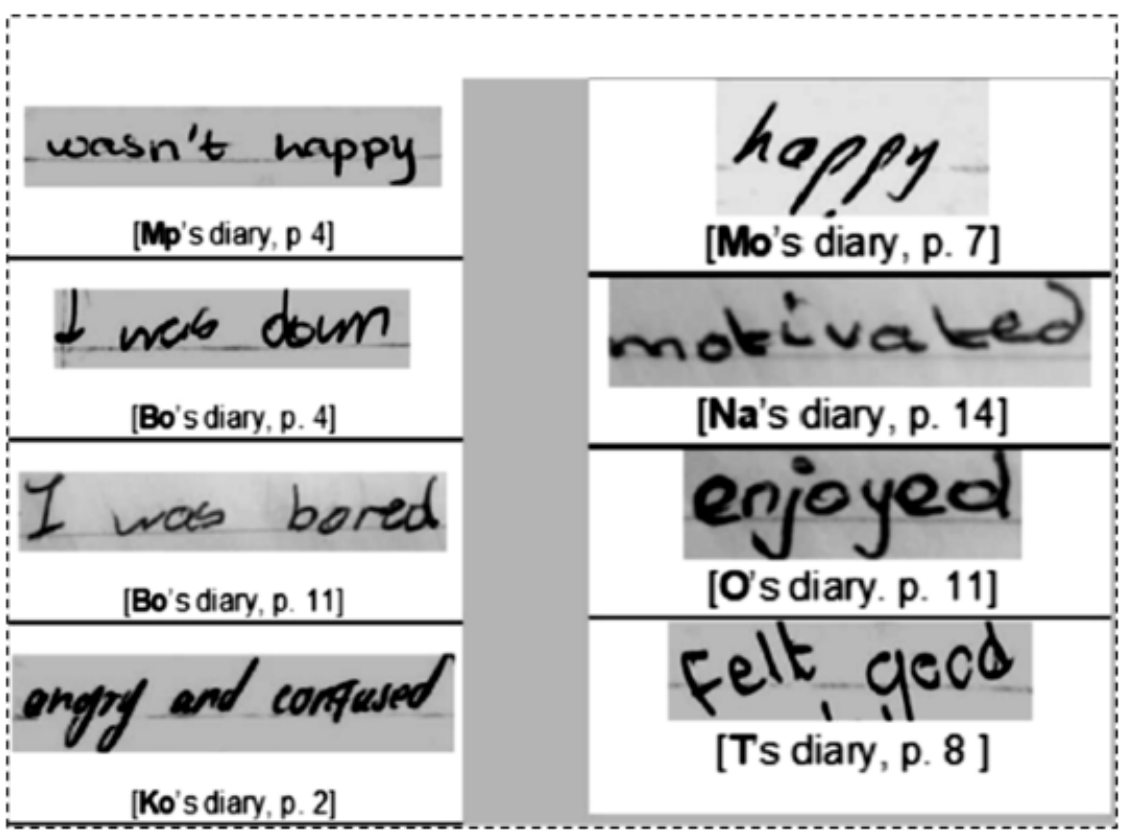

Figure 3. Students' feelings towards the geometry lessons

In contrast, experimental group students used words such as 'amazing', 'very good', 'nice', 'wonderful', 'excellent', 'fun and beneficial' to describe the way Euclidean theorems and proofs were presented in their mathematics classes. The phrases in Figure 2 give evidence.

It can be seen from the foregoing reports that students who were taught by their teachers using conventional approaches had negative views about the way Euclidean theorems and proofs were taught in their mathematics classes. Conversely, students from experimental schools who were taught using Van Hiele theory-based instruction gave positive comments on the approach used to teach Euclidean theorems and proofs in their mathematics classes.

\section{Students' records of their feelings towards the geometry lessons}

Analysis of control group students' diary reports revealed that they were not happy with the way Euclidean geometry theorems and proofs were taught in their mathematics classrooms. On the other hand, diarists from the experimental group recorded positive feelings about the way geometry lessons were delivered in their mathematics classrooms (see Figure 3).

Simply knowing that control group students were not happy with conventional approaches to teaching Euclidean theorems and proofs, and that their counterparts in the experimental group were satisfied with Van Hiele theory-based instruction, is not enough to help educators to improve. It is important to know exactly what teachers did in the control group mathematics classes which made students to be not 


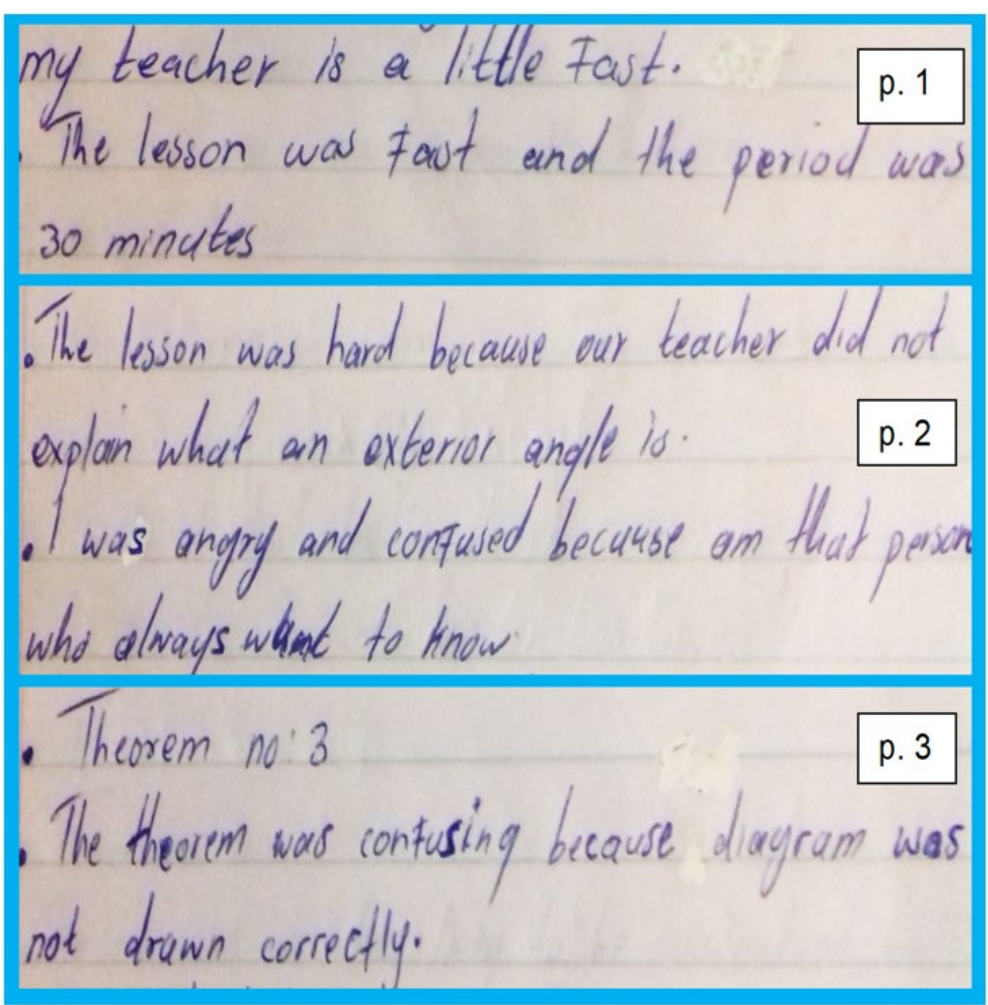

Figure 4. Ko's diary entries on unfavourable teaching practices

happy, bored, angry and confused. Such knowledge helps to inform teachers on pedagogical practices that are not favoured by the students. Knowing the pedagogical practices that made experimental group students to enjoy learning, feel good, happy and motivated, is also essential. Such knowledge informs teachers on what they need to adjust on their current pedagogical practices for better teaching and learning of Euclidean theorems and proofs.

\section{Favourable and unfavourable pedagogical practices}

A number of concerns were raised by control group students with regard to their teachers' pedagogical practices. Figure 4 shows segments of text extracted from participant Ko's diary record. The student complained about the fast pace of teaching, inadequate explanations and inaccurate drawings.

Student Bo recorded inadequate worked examples, use of lecture method, lack of teacher support, hasty and invariable teaching, among the pedagogical practices that impeded the learning of Euclidean theorems and proofs in their mathematics class. Figure 5 shows segments of text extracted from Bo's diary.

Participants from the experimental group schools who were taught using Van Hiele theory-based instruction recorded the pedagogical practices they liked the most. Figure 6 displays segments of text extracted from student $\mathrm{O}^{\prime}$ s diary record.

Student $\mathbf{O}$ enjoyed being actively engaged in lessons, discussing and working collaboratively with other students, showing respect for each other, and being taught by a teacher who is patient. The student was also impressed by the fact that the teacher explained the terminology of Euclidean geometry and what the topic is all about. Learning about the history of Euclidean geometry, why we study Euclidean geometry and its contribution to people's lives, motivated some students in the experimental group to want to know more about the topic.

Being given an opportunity to suggest and express their own views on what is taught, together with the use of multiple solution methods contributed positively to students' understanding of Euclidean theorems and proofs in the experimental group. Student Mo's diary reports testify (see Figure 7).

Student $\mathrm{Na}$ from the experimental group wrote extensively on the teaching practices that the student enjoyed the most. The student enjoyed being taught by a teacher who treated students equitably and allowed students to express themselves freely. Na recorded that the use of the Geometer's Sketch Pad (GSP) made geometry funny and easy. She enjoyed being taught by a teacher who is patient; one who makes sure that all students are moving at the same pace. The text in Figure 8 substantiates.

Student $\mathrm{Na}$ also liked being actively involved in the teaching and learning process. The student acknowledged that the teacher did not mind staying behind to clarify and re-teach some geometry concepts. Based on her Euclidean geometry learning experiences, student $\mathrm{Na}$ concluded that the teacher really knew how students' minds work. Figure 9 bears reference. 


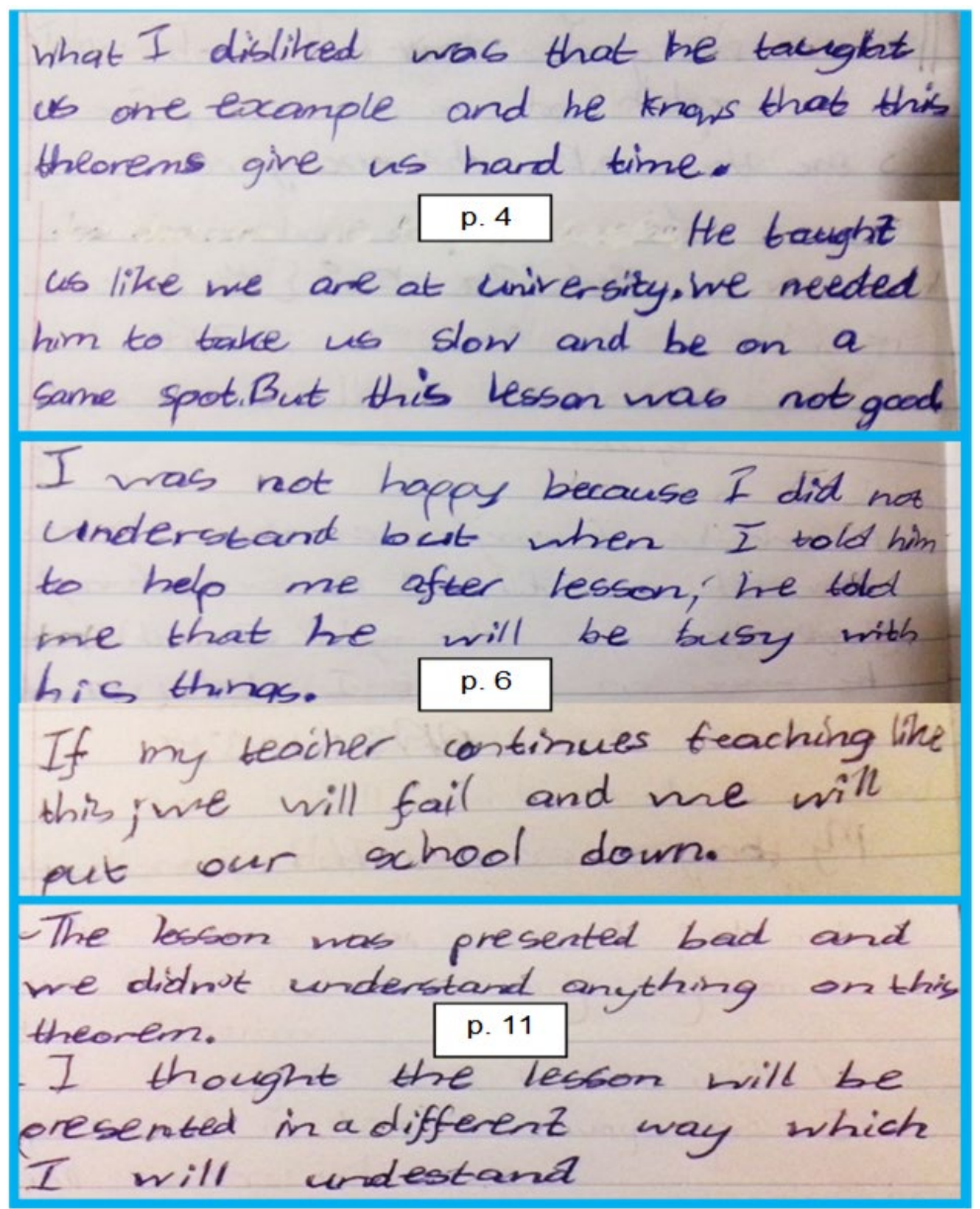

Figure 5. Bo's reports on unfavourable pedagogical practices

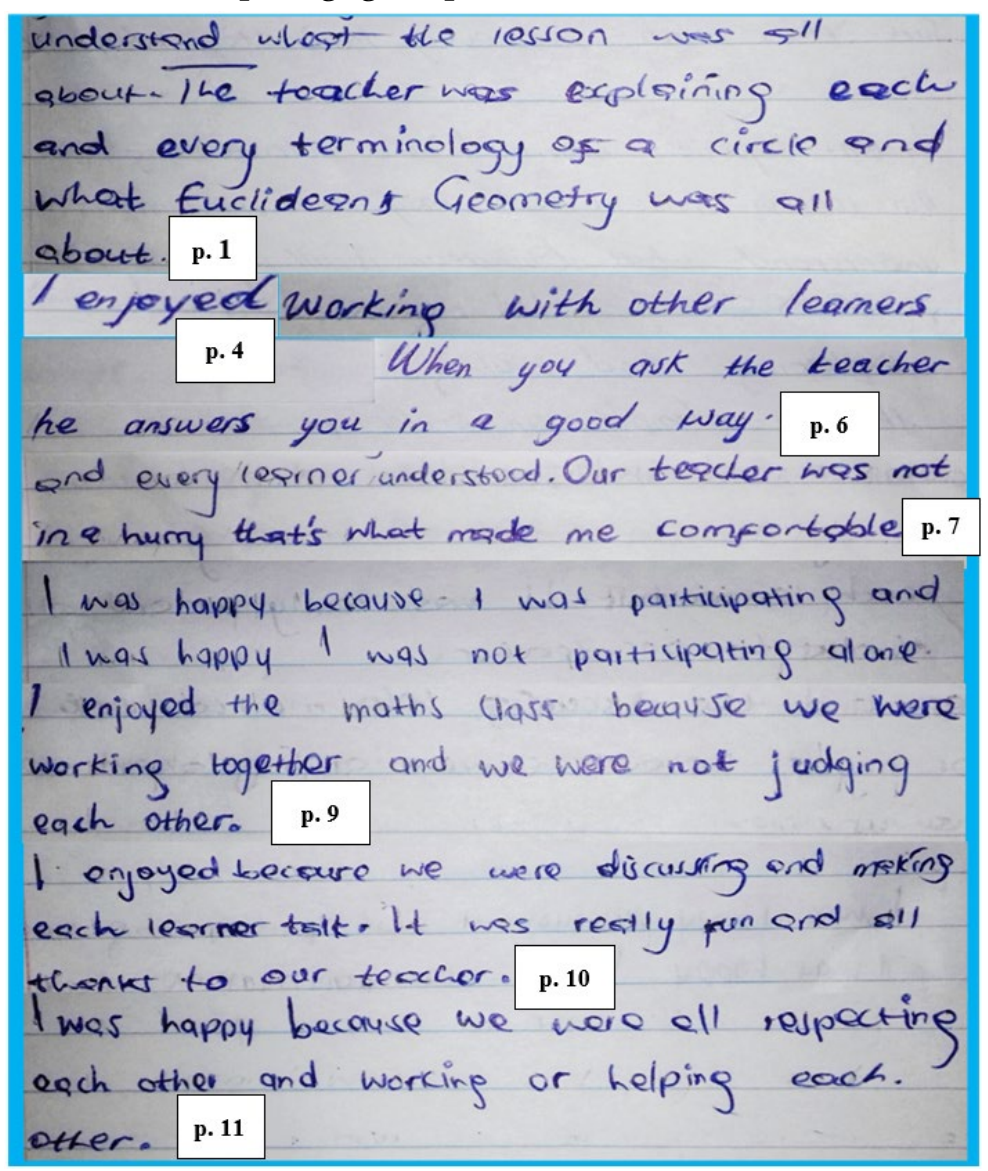

Figure 6. O's reports on favourable pedagogical practices 
Today I have learnt about the history of Euclidean Geometry. I did not

know much about it ( $E G$ ) but today

I was even alole to know its definitoon, why we study, it and how it contribute in our daily lives.

What I liked about if is that the trocher even qave us a Chance to pive ow own
suggestions and opinions. What I mostly learnt about this lesson is that maths has no limit in solutions. There are different ways to solve a p.11 problem and you can still get the same legit answer. And I thank the tecicher and my class mates for maleing me realise that

Figure 7. Mo's reports on favourable pedagogical practices

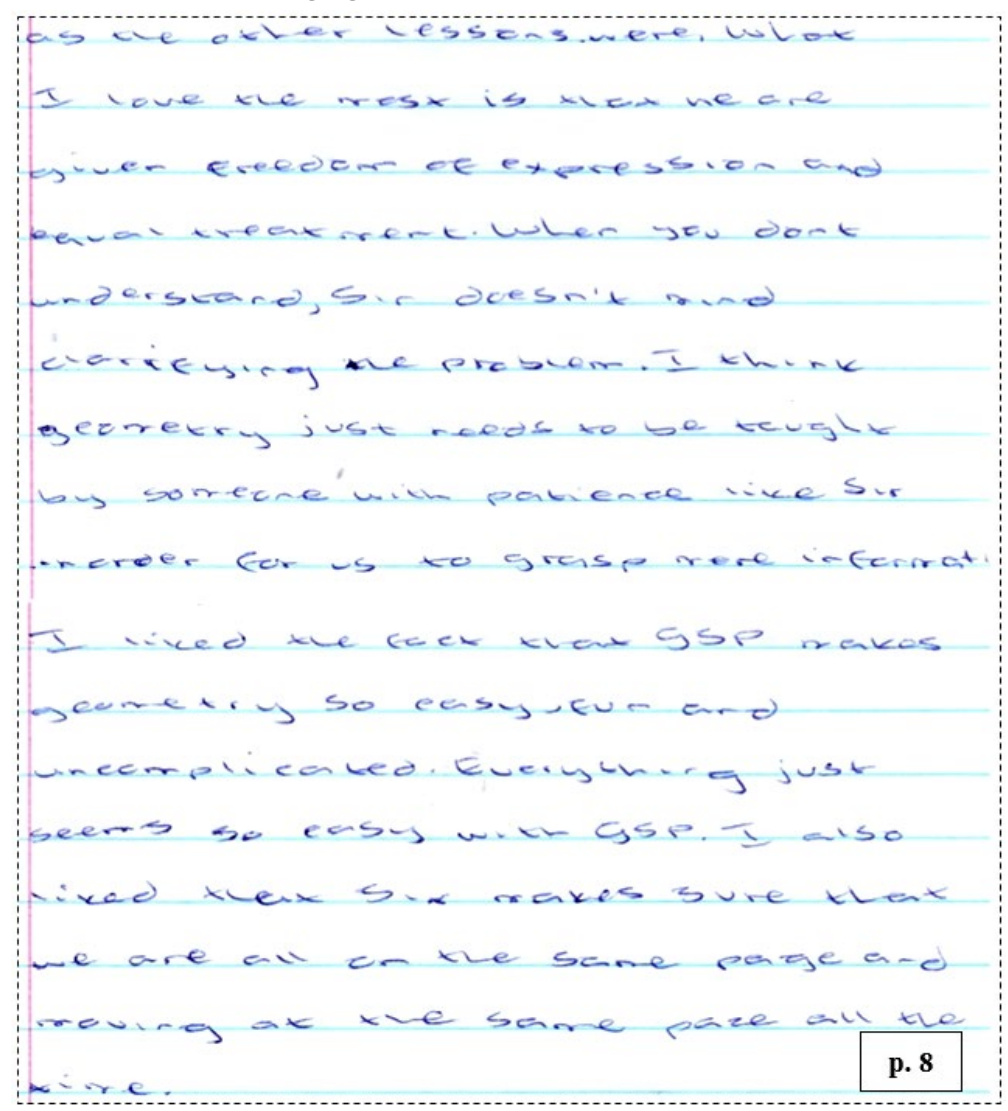

Figure 8. Na's reports on favourable teaching practices (1) 




Figure 9. Na's reports on favourable teaching practices (2)

While the study could have been concluded based only on the students' diary reports, research methodologists argue that the diary method should not be used in isolation (Woll, 2013). It is for this reason that focus groups discussions were used to supplement the diary method. This gave the researcher an opportunity to seek more details on some of the issues reported by students in their diaries. Part B of this section presents research findings from the group discussions.

\section{Part B: Focus Group Discussions}

The key questions that were asked by the moderator to facilitate the discussions were presented in the methodology section under data collection instruments. Students' verbal reports with regard to how Euclidean geometry lessons were taught in their mathematics classroom are presented and discussed in the next section.

\section{Students' verbal reports of their Euclidean geometry learning experiences}

Focus group participants from control group schools raised several concerns about the way Euclidean geometry and geometry proofs were taught in their mathematics class. Students from school C1 expressed the opinion that Euclidean geometry was not properly introduced. They frequently mentioned that key words such as chord and diameter were not explained prior to the introduction of theorems. One student cited this as the reason many students had difficulties with geometry proofs. The following scripts provide evidence:

Mp: ... in our school, when we were taught first time, our teacher didn't uh... he didn't explain... a chord is what? What is a diameter? Where do we use it? He wanted to introduce Theorem 1 without introducing the first things of geometry. That's why geometry gave us problems when coming to the proofs (FG C1, Position: 13-13).

Bo: Eh Sir! The way our teacher introduced this geometry, he didn't explain what is this... geometry. He didn't explain to us what kind of geometry is it ... and how some lines are called such as chord and ... a diameter. He just went straight to those theorems (FG C1, Position: 21-21).

Mp: ... our teacher thought that because we started doing geometry ... at those [lower] grades, I think it's Grade 9 or Grade $10 . .$. he thought maybe we know, what is chord, what is diameter, that's why he didn't think of touching those things ...only to find that even in the past we didn't even understand (FG C1, Position: 23 - 23).

Bo: Eh Sir! I think the teacher did some confusion at the first of this geometry... (FG C1, Position: 49 - 49).

Focus group participants from school C2 mentioned that learning Euclidean geometry and geometry proofs 
was difficult for them because their teacher rushed through the chapter trying to cover the syllabus and skipped some sections [or concepts] in the process. The following scripts attest:

Ho: They skipped other chapters [sections] of Euclidean geometry (FG C2, Position: 19 - 19).

... just like the last theorems like theorem 6 and $7, \ldots$ we didn't do them (FG C2, Position: 23 - 23).

Th: ... they did not teach us riders at all! They just teach us how the theorems [are] proved... but riders they didn't even touch them (FG C2, Position: 25 - 25).

$\mathbf{N}$ : I remember there was this time Sir was going ... somewhere else then he asked me to teach theorem 3,4 and 5. ...he never came back to those theorems and show [explain] them to the whole class. I just took a book... write what's on the book and then I sat down (FG C2, Position: 27 - 27).

L: Some of us we find it difficult to understand because they are trying to cover the syllabus (FG C2; Position: 45 - 45).

Most of the views expressed by participants from the control group here are consistent with what students recorded in their diaries. An additional point mentioned here is the view that some teachers skipped some sections of Euclidean geometry.

While focus group participants from the control group reported negative learning experiences, their counterparts from the experimental group who were taught using Van Hiele theory-based instruction unanimously agreed that Euclidean geometry was taught well in their mathematics classes. The following scripts bear reference:

O: I think they taught us in a good way. If I was going to rate, I would rate 10 over 10 because I understood everything about Euclidean geometry and geometry proofs. And now I have more knowledge, ... (FG E1, Position: 10 - 10).

Ha: ... from my point of view, I think Euclidean geometry was taught very well in our mathematics class as we were able to solve the riders (FG E2, Position: 12 12).

T: I think the way they taught us Euclidean geometry was very good... because at one point they would give (us) activities. They would leave us for like one hour ... we will try to figure out how to come up with solutions, ...that made us be a bit witty [wise]...because well they don't really give us answers to the question at first. They leave us then we will be able to discuss it with others, ... (FG E1, Position: 14 - 14).

The comments made by experimental group students here resonate with their diary evaluations of how Euclidean geometry lessons were presented in their mathematics classes.
The next sub-section describes how participants felt about the way Euclidean geometry and geometry proofs were taught in their mathematics class.

\section{Students' verbal descriptions of their feelings and emotions}

Many focus group participants from control group schools expressed negative feelings about the way Euclidean geometry and geometry proofs were taught in their mathematics classes. Participants from school C2 reported that they felt bad about the way they were taught:

Te: Sir, I don't feel good because I don't know some of the theorems and there is a need whereby, I have to know especially riders. And riders have a lot of marks whereby when I can understand all of the theorems then I will be able to get the marks that are there (FG C2, Position: 31 - 31).

Th: I feel bad because they did not teach us riders. Many question papers come with lots of riders. I can't write something that I don't know that's why we lose marks at geometry (FG C2, Position: 41 - 41).

$\mathbf{N}$ : I also feel bad because eh, some of us learners we prefer that eh, teachers should teach us and then that's where we get to understand the concepts and then when we go home, we just revise and practise that (FG C2, Position: 43 - 43).

Te: It is heart-breaking when I look at the question paper, I see a lot of marks but eish! I can't reach them because I don't have that knowledge (FG C2, Position: 65 65).

Focus group participants from school C1 reported feelings of confusion:

Mp: I feel confused because when our teacher teaches us, we understand but when we get home, nothing! Like, we don't understand anything because the teacher is no more there (FG C1, Position: 29 - 29).

Bo: I feel like this geometry is understandable but our teacher didn't be specific on that geometry, that's why we are a little bit confused (FG C1, Position: 31 31).

It can be seen from the above statements that focus group participants from control group schools were unhappy with the way Euclidean geometry and geometry proofs were taught in their mathematics classes, just as they reported in their diaries. The students were fully aware that Euclidean geometry constitutes a lot of marks in their examination papers but were frustrated at their teachers' failure to help them understand the topic.

Contrastingly, focus group participants from the experimental group schools felt good about the way Euclidean geometry and geometry proofs were taught in their mathematics classes. The following scripts provide proof: 
Mo: I feel very good about it because... as they taught us, we were not only like listening to the teacher alone, we were giving our own thoughts, and our own ... views from what we think about them... I feel good about it because we were able to do ... things that I never thought I can do in my life... Firstly, when they introduced us to this topic of Euclidean geometry, I thought it was a difficult part but as I got to explore ... as they were teaching us about it. I was able to be free around my mates and then I succeeded, ... I can do most of the things. Yah, I feel good because it brought a good experience ... in my life (FG E2, Position: 16 - 16).

Ch: I felt privileged to have been taught Euclidean geometry in this maths class because that GSP... really works like, really helped me to be more interested in Euclidean geometry because those things I was doing them myself practically not just theoretically (FG E2, Position: 18 - 18).

T: I feel good...because they teach us how to solve problems not only in the mathematics class but then in real life... (FG E1, Position: 18 - 18).

Based on these responses, experimental group students' positive feelings can be attributed to the following aspects: being actively involved in the learning process; sharing their own views and thoughts on what is being taught; exploring geometry concepts freely in the presence of their classmates; achieving what they thought they cannot achieve; learning Euclidean geometry concepts practically, not just theoretically, and lastly; seeing the connection between Euclidean geometry concepts and real life situations. These views are consistent with what the students recorded in their diaries.

To gain more insight into students' views and feelings, focus group participants from both experimental and control group schools were asked to specify exactly what they liked or disliked about the way Euclidean geometry and geometry proofs were taught in their mathematics class. The students mentioned a wide range of teaching and learning experiences which they thought had the greatest impact on their views and feelings. The next sub-section presents the most striking responses that emerged from the group discussions.

\section{Students' verbal reports on favourable and unfavourable teaching practices}

When prompted to discuss what they liked and disliked about how Euclidean geometry and geometry proofs were taught in their mathematics class, participants from control group schools indicated that they did not like the teaching approaches used in their mathematics classes. The key concerns raised by participants included: teachers teaching at a fast pace to cover the syllabus; teachers skipping some sections of the Euclidean geometry chapter; teachers being impatient and insensitive to the needs of slow learners; teachers making negative comments; and the teachers themselves showing a negative attitude towards Euclidean geometry. These issues are evident in the following comments:

Th: I didn't like the way they taught us because ... they are fast and didn't think that we have slow learners (FG C2, Position: 47 - 47).

Ho: I don't like it because they summarise those chapters and when they summarise those chapters some of the things of Euclidean geometry...decrease our marks. When we go and tell them you did not teach us this, they say we must go and study... we can't go and study for ourselves, ... they are supposed to teach us those things. (FG C2, Position: 51 - 51).

Th: Uhm, eish! Sometimes... when we approach him and explain that Sir ... we don't understand, he tells us that he has another class to attend (FG C2, Position: $71-71)$

Ho: ...when we seek help from him, he shows us that attitude of saying- 'I taught you this in class' ... He is impatient with us (FG C2, Position: 75 - 75).

They should stop using words of discouraging learners in class. They love to discourage learners. ... they tell us that I [we] cannot pass. If they tell me that I cannot pass I will stop coming to school. I don't see the difference! (FG C2, Position: 89 - 89).

Co: ... when we tell him that we don't understand, ... he says he has to finish the syllabus... so that when we write exams, we will not tell him that we didn't do this and that...he says he can't stick on Euclidean geometry forever. He has to move on to other chapters (FG C2, Position: 73 - 73).

L: ... if you want to ...ask a question, they say you did this last year and something that we did only once and we don't understand it. We need more knowledge to understand but they say you did it... (FG C2, Position: 95 - 95).

Co: The teachers are failing us...they forget that we are slow, that's why we ask but then the teachers are impatient with us (FG C2, Position: 97 - 97).

Mp: ...mostly when he teaches geometry, he changes his attitude but when he teaches other topics..., I understand very well (FG C1, Position: 51 - 51).

The comment by student $\mathbf{M p}$ from school $\mathrm{C} 1$ that the teacher changed his attitude when teaching Euclidean geometry raises questions on the teacher's ability to teach the topic.

While focus group participants from control group schools reported teaching practices they did not like, students from experimental group schools mentioned the pedagogical practices they enjoyed. These included among others: the use of Geometer's Sketchpad to investigate theorems; teaching at a slow and moderate pace; being sensitive to students' learning needs; active engagement of all students in the class; and a free 
learning environment where making mistakes and giving wrong answers is part of the learning process. Participants' responses reflecting these ideas included:

Ch: Eh, that part when we were taught in our maths class when we were using computers using the GSP software, ... was really good for us as learners because it wasn't like reading those theorems in a book. We were actually seeing them first-hand. We were actually measuring those angles. In our books those things are not drawn to scale, you just read them and all you do is just memorise but that GSP software you can see them straight and you can measure those angles, (and) the sides, you can see what exactly they are talking about (FG E2, Position: 14 - 14).

O: What I like about the way we were taught is..., our teacher was not in a hurry. He was patient and if a learner didn't understand he could explain more and give more examples (FG E1, Position: 24 - 24).

Na: ...what I like was that everybody was able to participate in the lesson... Sir wrote statements on the chalkboard and everyone had a right or freedom to go there and fill the correct reason for that particular statement so the class was alive ... we were jumping up and down, back and forth to the chalkboard... I liked everything about how Euclidean geometry was taught (FG E1, Position: 22 - 22).

T: Well, what I like is the participation of everyone. That was on another level because well, we understood what Euclidean geometry was all about. In that way we were able to participate like all the time. We were even fighting over the chalk at times. That is what I liked (FG E1, Position: 26 - 26).

Mo: ... the teacher made us to be free in class ... he was not that strict like all the time...he encouraged us to work in pairs so that we can help each other and he did not discourage us in any way or make me or make them [students] feel uncomfortable in a way whereby we cannot even raise our hands ... we were fighting [competing] to write on the chalkboard... (FG E2, Position: 26 - 26).

Na: ...what Sir did to make us feel comfortable was...telling us that no one is right and nobody is wrong. So, whenever you feel like answering you must do so even if you do not feel like your answer is right... (FG E1, Position: 36 - 36).

T: He is always free with us... So, that is what I like about him. He's always a free man... most of us are not afraid to go towards him and say this is the problem that I came across, so how can I try to solve this particular problem (FG E1, Position: 38 - 38).

Most of the views expressed by the students here resonate with results obtained from students' diary reports. In the last part of the focus group discussions, participants were asked to describe their prevailing attitudes towards Euclidean geometry and geometry proofs based on their learning experiences. A number of valuable and insightful responses were given, the details of which are presented in the next sub-section.

\section{Students' attitudes towards Euclidean geometry and geometry proofs}

When control group students were asked to describe their prevailing attitudes towards Euclidean geometry based on their learning experiences, most of responses given were negative. Dominant responses that emerged from discussions with control group participants included:

$\mathbf{N}$ : ...I have a bad attitude towards Euclidean geometry because I only understand few theorems, theorem 1, 2, maybe 3, but the rest - ai! (FG C2, Position: 55 - 55).

L: ...I have a bad attitude because when I try it at home, I find it very difficult... I give up! (FG C2, Position: 57 - 57).

Co: I have a bad attitude because I got some theorems but to prove that theorem 6 and 7 , and riders, I don't get it because is difficult (FG C2, Position: 63 - 63).

Mp: I have a bad attitude towards geometry because I find it difficult to understand what is being taught (FG C1, Position: 39 - 39).

In contrast, participants from experimental group schools reported their attitude towards Euclidean geometry and geometry proofs to have changed from negative to positive due to the influence of the Van Hiele theory-based model of instruction. The following comments provide evidence:

O: ...my attitude was negative (at first) because I didn't know like (how) to solve Euclidean geometry (problems). I didn't know what Euclidean geometry is all about. So, when our teacher taught us, my attitude changed to being positive (FG E1, Position: $30-30)$.

Mo: ... at first, I was being negative about myself... how am I going to solve these things...then, as I got to explore...solving riders in many different ways... then that ... just got me a positive attitude because now I am able to do many things of geometry (FG E2, Position: 22 - 22).

T: Right now, my attitude is not the way it was before. It is more than positive (FG E1, Position: 28 - 28).

Na: I can now tackle Euclidean geometry questions on my own and get them right... my skills have also improved. I am able to interpret diagrams more accurately and apply the knowledge that I have acquired in previous days... So Euclidean geometry is not actually a difficult thing... (FG E1, Position: 4 $-4)$.

My attitude at first was not good because I felt like Euclidean geometry was gonna defeat me because it's something I ...never did before. But as time went on my attitude started to change... Then I started 
improving and started feeling better about myself... (FG E1, Position: 32 - 32).

\section{Part C: Emerging Issues}

Students from control group schools were not happy with the way Euclidean geometry and proof lessons were presented in their mathematics classes. Comments such as 'The lesson was fast' and 'He taught us like we are at university' provide evidence to the continued use of teacher-centred approaches in the teaching of Euclidean geometry in secondary schools. This confirms what was reported in literature by Abdullah Zakaria (2013), Bramlet and Drake, 2013, and Siyepu (2014). As the teacher moved fast to cover the syllabus, the students were left behind. To make matters worse, the teacher in one of the control group schools was not willing to provide additional support to students who needed extra attention. When students approached the teacher for help outside lesson time, the teacher gave all sorts of excuses to avoid helping the students. One student from school C1 observed that the teacher changed his attitude and behaved unusually when teaching Euclidean geometry. This, together with the fact that the teacher in school C2 skipped some sections of Euclidean geometry, points to the view that the teachers themselves could be having challenges with not only the methodology but also the content of Euclidean geometry. This is not surprising given that some teachers have no previous contact with the topic as reported by Govender (2014).

The teacher in school C1 moved straight into proving theorems without checking if students had mastered the prerequisite knowledge. This contradicts what the Van Hiele theory proposes. The teacher's failure to explain the meaning of key words such as chord and diameter before introducing theorems made it difficult for some students to understand proofs. The Van Hiele theory stresses the importance of developing the language of the Euclidean geometry. The role of language in learning mathematics is a widely researched topic (see for example, Craig \& Morgan, 2015; Mulwa, 2014; Naziev, 2018; Robertson \& Graven, 2019). According to Robertson and Graven (2019), language can "either include or exclude certain groups of students from genuine opportunities for mathematical sense-making" (p. 77). Thus, by not teaching students the terminology of Euclidean geometry, teachers exclude some students from understanding geometry concepts.

Teaching Euclidean geometry using traditional methods made students in the control group schools to feel discouraged, bored, angry, confused and heartbroken during lessons, resulting in a negative and bad attitude towards the topic. Comments such as 'We didn't understand anything on this theorem' and 'I thought the lesson will be presented in a different way which I will understand' call for teachers to change their approaches to teaching Euclidean geometry and try something different.
In stark contrast to the views expressed by control group students, students from the experimental group schools who were taught using the Van Hiele theorybased model were satisfied with the approach used to teach Euclidean geometry in their classes. Students in the experimental group used words such as 'very good', 'wonderful' and 'excellent' to evaluate how they were taught. The Van Hiele theory-based approach left students feeling 'happy' and 'motivated', with a positive attitude towards the topic. Giving students information about the origin of Euclidean geometry, why the topic should be studied in schools, and its application in real life situations, made students to gain interest in learning the topic. The use of the Geometer's Sketch pad (GSP) to explore geometry concepts made Euclidean geometry lessons to be 'fun and beneficial'. In addition, the GSP offered students an opportunity to re-invent the theorems and see the results for themselves instead of memorizing theorems from the textbook.

Experimental group students enjoyed learning in a free environment where they exercised freedom of expression, and making mistakes was part of learning. This is in line with the Van Hiele's idea of free orientation. Students in the experimental group reported that they enjoyed being taught by a teacher who was patient and not in a hurry. Thus, implementing Van Hiele theory-based instruction requires the teacher to value students' understanding more than syllabus coverage. Experimental group students mentioned that the teacher made sure that students were 'on the same page and moving at the same pace all the time' (see Figure 8). The pace of teaching was regulated by the students' level of understanding, not the pressure to finish the syllabus in a stipulated time-frame.

Discussing and sharing multiple ways to solve riders during the integration phase, and working collaboratively in pairs and groups without judging each other, are among the pedagogical practices favoured by students in the experimental group. Students in the experimental group acknowledged the teacher's readiness to support and help students who needed extra attention. They also reported that they were treated equitably. The active engagement of students in the learning process as opposed to just listening to the teacher, was also liked by students in the experimental group (see Figure 6 \& Figure 9). Last but not least, Van Hiele theory-based instruction changed students' attitude towards Euclidean geometry and proofs from being negative to positive.

From the foregoing discussion, it can be seen that traditional approaches to teaching Euclidean geometry theorems and proofs impede learning progress. Based on the students' reflections, Van Hiele theory-based instruction seems to offer more benefits to the students than the use of traditional methods in the teaching and learning of Euclidean geometry and proofs. 


\section{RECOMMENDATIONS AND CONCLUSION}

Based on the outcomes of this study, the following recommendations are proposed:

* Mathematics teachers need training on how to implement unconventional teaching approaches such as Van Hiele theory-based instruction in teaching Euclidean geometry.

* Students should regularly be given an opportunity to voice their concerns in the teaching and learning of Euclidean geometry. Feedback from the students can be used to realign instruction to meet the learning needs of the students.

* There is need to investigate Euclidean geometry competencies of individual mathematics teachers to identify areas where they may need to be supported.

In conclusion, mathematics teachers should remember that pedagogical content knowledge is dynamic. New research findings may require teachers to part ways with teaching approaches and practices they have used for decades to embrace new pedagogical knowledge. It is every mathematics teacher's responsibility to stay up to date with emerging views in mathematics education. A good mathematics teacher is a life-long learner, who engages in continuous research to find new and better ways to teach different mathematics topics. Euclidean geometry cannot be taught like any other mathematics topic. It requires teachers to have special pedagogical knowledge for teaching this valuable mathematics topic.

\section{REFERENCES}

Abdullah, A. H., \& Zakaria, E. (2013). Enhancing students' level of geometric thinking through Van Hiele's phase-based learning. Indian Journal of Science and Technology, 6(5), 4432-4446. https://doi.org/10.17485/ijst/2013/v6i5.13

Abrahams, K., \& Matthews, T. (2011). Child rights manual: Handbook for parliamentarians. Cape Town: Parliament of the Republic of South Africa.

Adeniji, S. M., Ameen, S. K., Dambatta, B., \& Orilonise, R. (2018). Effects of mastery learning approach on senior school students' academic performance and retention in circle geometry. International Journal of Instruction, 11(4), 951-962. https://doi.org/ 10.12973/iji.2018.11460a

Al-Khateeb, M. A. (2016). The extent of mathematics teachers' awareness of their students' misconceptions in learning geometrical concepts in the intermediate education stage. European Scientific Journal, 12(31), 357-372. https:/ / doi.org/10.19044/esj.2016.v12n31p357
Anney, V. N. (2014). Ensuring the quality of the findings of qualitative research: looking at trustworthiness criteria. Journal of Emerging Trends in Educational Research and Policy, 5(2), 272-281.

Armah, R. B., Cofie, P. O., \& Okpoti, C. A. (2018). Investigating the effect of Van Hiele phase-based instruction on pre-service teachers' geometric thinking. International Journal of Research in Education and Science (IJRES), 4(1), 314-330. https://doi.org/10.21890/ijres.383201

Baiduri, B., Ismail, A. D., \& Sulfiyah, R. (2020). Understanding the concept of visualization phase student in geometry learning. International Journal of Scientific E Technology Research, 9(2), 2353-2359.

Baral, S., Uprety, S., \& Lamichhane, B. (2016, March). Focus group discussion. Retrieved from Herd: http:/ / www.herd.org.np/uploads/frontend/Pub lications/PublicationsAttachments1/1480653060Focus\%20Group\%20Discussion_0.pdf

Bazeley, P., \& Jackson, K. (2013). Qualitative data analysis with NVIVO. London: Sage Publications Ltd.

Bill, A., \& Giles, D. (2016). Repositioning diagnostic school reviews using appreciative inquiry: A way of eliciting student voice for school improvement. Journal of Educational Leadership, Policy and Practice, 31(1), 165-179.

Bonnie, L., \& Lawes, E. (2016). Assessing students' maths self-efficacy and achievement. Assessment News, 2, 60-63. https://doi.org/10.18296/set.0048

Bowie, L. (2009, June). What is Mathematics Paper 3 for? Marang News, 5.

Bramlet, D. C., \& Drake, C. T. (2013). The role of proof in the curriculum. Journal of Mathematical Sciences and Mathematics Education, 8(1), 62-72.

Busher, H. (2012). Students as expert witnesses of teaching and learning. Management in Education, 26(3), 113-119. https://doi.org/10.1177/ 0892020612445679

Bytheway, B. (2012). The use of diaries in qualitative longitudinal research. In B. Neale, \& K. Henwood (Eds.), Timescapes Methods Guides Series 2012 Guide No. 7. Leeds: Economic and Social Research Council. Retrieved from http://www.timescapes. leeds.ac.uk/assets / files/methods-guides / timescapes-bytheway-use-of-diaries.pdf

Cato, N. (2018). Student voice in secondary schools: Purpose, value and characteristics. Auckland, New Zealand: Unitec Institute of Technology.

Craig, T., \& Morgan, C. (2015). Language and communication in mathematics education. In S. J. Cho (Ed.), The Proceedings of the 12th International Congress on Mathematics Education (pp. 529-533). Cham: Springer. https://doi.org/10.1007/978-3319-12688-3_53 
De Villiers, M., \& Heideman, N. (2014). Conjecturing, refuting and proving within the context of dynamic geometry. Learning and Teaching Mathematics, 17, 20 26.

Dell EMC. (2018, May). Empowering student voice and choice to deliver personalized education. Student Voice and Choice Whitepaper, 1-14.

Department of Education and Training. (2018). Amplify: Empowering students through voice, agency and leadership. East Melbourne, Victoria: State of Victoria.

Dilshad, R. M., \& Latif, M. I. (2013). focus group interview as a tool for qualitative research: an analysis. Pakistan Journal of Social Sciences, 33(1), 191-198.

Dube, N. V. (2016). Teachers' experiences of the implementation of the mathematics curriculum and assessment policy statement at the further education and training (FET) phase: Case Study. University of Fort Hare, Faculty of Education. East London: University of Fort Hare.

Duke, J. (2012). Joining the dots: Piloting the work diary as a data collection tool. Issues in Educational Research, 22(2), 111-126.

Elo, S., Kääriäinen, M., Kanste, O., Pölkki, T., Utriainen, K., \& Kyngäs, H. (2014). Qualitative content analysis: A focus on trustworthiness. SAGE Open January-March 2014, 1-10. https:/ / doi.org/10.1177/ 2158244014522633

Engelbecht, J., Harding, A., \& Phiri, P. (2010). Are OBEtrained learners ready for university mathematics? Pythagoras, 72, 3-13. https://doi.org/10.4102/ pythagoras.v0i72.16

Govender, R. (2014). Rider strategies for solving school geometry problems. In M. Lebitso, \& A. Maclean (Eds.), Proceedings of the 20th Annual National Congress of the Association for Mathematics Education of South Africa: Demystifying Mathematics (pp. 4-5). Kimberley: AMESA.

Holloway, I., \& Wheeler, S. (2010). Qualitative research in nursing and healthcare. Oxford, UK: Blackwell.

Jones, K., Fujita, T., \& Kunimune, S. (2012). Promoting productive reasoning in the teaching of geometry in lower secondary school: Towards a future research agenda. In S. J. Cho (Ed.), Pre-proceedings of the 12th International Congress on Mathematical Education ICME-12 (pp. 2387-2396). Seoul, Korea: ICME.

Kanandjebo, L. N., \& Ngololo, E. N. (2017). The effects of 'geometry sketchpad' on Grade 12 learners' performance in geometry. International Electronic Journal of Mathematics Education, 12(3), 735-747.

Keiler, L. S. (2018). Teachers' roles and identities in student-centered classrooms. International Journal on STEM Education, 5(1), 1-20. https://doi.org/ 10.1186/s40594-018-0131-6

Knight, W. E. (2012). Using focus groups. In W. E. Knight, \& R. A. Costomiris (Ed.), Ball State University Assessment Workbook (pp. 49-54). Muncie: Office of Institutional Effectiveness, Ball State University. Retrieved from https://www.bsu.edu /-/media/www/departmentalcontent/effectiven ess/pdfs/wkbk/assessment $\% 20$ workbook $\% 20$ $\%$ 2020121.pdf?la=en

Köğce, D., Aydın, M., \& Yıldız, C. (2010). The views of high school students about proof and their levels of proof: The case of Trabzon. Procedia Social and Behavioral Sciences, 2, 2544-2549. https://doi.org/ 10.1016/j.sbspro.2010.03.370

Krueger, R. A. (2002, October). Designing and conducting focus group interviews. St. Paul, MN: University of Minnesota. Retrieved from https:// www.eiu.edu/ihec/Krueger-FocusGroup Interviews.pdf

Kuhn, G. (2016, November 16). What is a moderator's guide? Focus groups upstate NY. Retrieved from Drive Research: https:/ / www.driveresearch.com/ single-post/2016/10/30/What-is-a-ModeratorsGuide-Focus-

Machisi, E., \& Feza, N. N. (in press). Van Hiele theorybased instruction and Grade 11 students' geometric proof competencies. Contemporary Mathematics and Science Education.

Mensah-Wonkyi, T., \& Adu, E. (2016). Effect of the inquiry-based teaching approach on students' understanding of circle theorems in plane geometry. African Journal of Educational Studies in Mathematics and Sciences, 12, 61-73.

Mostafa, M., Javad, L. M., \& Reza, O. H. (2017). The effect of Van Hiele theory-based teaching educational package on achievement goal orientation of student teachers. Review of European Studies, 9(1), 93-105. https:/ / doi.org/10.5539/res.v9n1p93

Mouton, N., Louw, G. P., \& Strydom, G. L. (2012). A historical analysis of the post-apartheid dispensation education in South Africa (1994-2011). International Business and Economics Research Journal, 11(11), 1211-1222. https://doi.org/10.19030/iber. v11i11.7369

Mudaly, V. (2016). Pre-service teachers' understanding of the concept of proof. International Scientific Researches Journal, 72(5), 137-158. https:/ / doi.org/ $10.21506 / j$.ponte.2016.5.15

Mukamba, E., \& Makamure, C. (2020). Integration of GeoGebra in teaching and learning geometric transformations at Ordinary Level in Zimbabwe. Contemporary Mathematics and Science Education, 1(1), ep20001. https:/ / doi.org/10.30935/conmaths /8431 
Mulwa, E. C. (2014). The role of language of mathematics in students' understanding of number concepts in Eldoret Municiplaity, Kenya. International Journal of Humanities and Social Science, 4(3), 264-274.

Mwadzaangati, L. (2015). Mathematical knowledge for teaching geometric proof: Learning from teachers' practices. Proceedings of the Ninth Congress of the European Society for Research in Mathematics Education (pp. 3308-3308). Prague, Czech Republic: CERME.

Naidoo, J., \& Kapofu, W. (2020). Exploring female learners' perceptions of learning geometry in mathematics. South African Journal of Education, 40(1), 1-11. https:// doi.org/10.15700/saje.v40ns2a 1717

Naziev, A. (2018). The role of language in teaching and learning mathematics. BRAIN-Broad Research In Artificial Intelligence and Neuroscience, 9(1), 114-124.

Ndlovu, M. (2013). The learning of geometry as moving from one thinking level to the next: revising Van Hiele. In Z. Davies, \& S. Jaffer (Ed.), Proceedings of the 19th Annual Congress of the Association for Mathematics Education of South Africa (pp. 277-279). Cape Town: AMESA.

Ngirishi, H., \& Bansilal, S. (2019). An exploration of high school learners' understanding of geometric concepts. Problems of Education in the 21st Century, 77(1), 82-96. https://doi.org/10.33225/pec/ 19.77 .82

Olivier, W. (2013, May). Reflection on the training of teachers for the CAPS mathematics curriculum - a brief report. Retrieved from SAMF: http:/ / www.samf.ac.za/documents /CAPS_math ematics_curriculum.pdf

Olivier, W. (2014, April). Reflections on the Implementation of CAPS Mathematics in the Classroom. Retrieved from SAMF: http:/ / www.samf.ac.za/documents / Reflections_on_implementation_of_CAPS_Mathe matics_in_the_Classroom.pdf

Oueini, S. (2019). The impact of intelligent tutoring software on geometry students. University of South Carolina. California: University of South Carolina Scholar Commons.

Padayachee, P., Boshoff, H., Olivier, W., \& Harding, A. (2011). A blended learning Grade 12 intervention using DVD technology to enhance teaching and learning of mathematics. Pythagoras, 32(1), 1-8. https:// doi.org/10.4102/pythagoras.v32i1.24

Pearson, D., \& Vossler, A. (2016). Methodological issues in focus group research. Counselling Psychology Review, 31(1), 8-16.

Rausch, A. (2014). Using diaries in research on work and learning. In C. Harteis, A. Rausch, J. Seifried, C. Harteis, A. Rausch, \& J. Seifried (Eds.), Discourses on Professional Learning: On the Boundary Between
Learning and Working (pp. 341-366). Dordrecht: Springer.

Reid, S., \& Mash, B. (2014). African primary care research: Qualitative interviewing in primary care. African Journal of Primary Health Care and Family Medicine, 6(1), 1-6. Retrieved from https:/ / doi.org/10.4102/phcfm.v6i1.632

Rennie Center for Education Research and Policy. (2019). Student voice: How young people can shape the future of education. Boston, MA: Rennie Center for Education Research and Policy.

Robertson, S.-A., \& Graven, M. (2019). Language as an including or excluding factor in mathematics teaching and learning. Mathematics Education Research Journal, 32(1), 77-101. https://doi.org/ 10.1007 / s13394-019-00302-0

Saldana, J. (2013). The coding manual for qualitative researchers. London: Sage Publications Ltd.

Sheble, L., \& Wildemuth, B. (2009). Research diaries. In B. Wildemuth (Ed.), Applications of Social Research Methods to Questions in Information and Library Science (pp. 211-221). Santa Barbara, CA: Libraries Unlimited.

Siyepu, S. (2014). Analysis of Van Hiele's theory in circle geometry: A Focus in FET level. In M. Lebitso, \& A. Maclean (Eds.), Proceedings of the 20th Annual National Congress of the Association for Mathematics Education of South Africa: Demystifying Mathematics (pp. 61-63). Kimberley: AMESA.

Sun, H. (2014). Rapport and its impact on the disclosure of sensitive information in standardized interviews. University of Maryland, Faculty of Graduate School. College Park: University of Maryland.

Tachie, S. A. (2020). The challenges of South African teachers in teaching euclidean geometry. International Journal of Learning, Teaching and Educational Research, 19(8), 297-312. https:/ / doi.org/10.26803/ijlter.19.8.16

Tahani, A. (2016). Effects of Van Hiele Model in geometric concepts acquisition: The attitudes towards geometry and learning transfer effect of the first three grades students in Jordan. International Education Studies, 9(4), 87-98. https:/ / doi.org/10.5539/ies.v9n4p87

Thomas, E., \& Magilvy, J. K. (2011). Qualitative rigour or research validity in qualitative research. Journal for Specialists in Pediatric Nursing, 16(2), 151-155. https:/ / doi.org/10.1111/j.1744-6155.2011.00283.x

Usman, H., Yew, W. T., \& Saleh, S. (2019). Effects of Van Hiele's phase-based teaching strategy and gender on pre-service mathematics teachers' attitude towards geometry in Niger State, Nigeria. African Journal of Educational Studies in Mathematics and Sciences, 15(1), 61-75. 
Van Hiele, P. M. (1984). A Child's thought and geometry. In D. Fuys, D. Geddes, \& R. Tischler (Eds.), English Translation of Selected Writings of Dina Van HieleGeldof and Pierre M. Van Hiele (pp. 247-256). Brooklyn, NY: Brooklyn College.

Van Hiele-Geldof, D. (1984). The didactic of geometry in the lowest class of secondary school. In D. Fuys, D. Geddes, \& R. Tischler (Eds.), English Translation of Selected Writings of Dina Van Hiele-Geldoff and Pierre M. Van Hiele (pp. 10-222). Brooklyn, NY: Brooklyn College.

Wang, X. (2013). Why students choose STEM majors: Motivation, high school learning and postsecondary context of support. American Educational Research Journal, 50(5), 1081-1121. https:/ / doi.org/10.3102/0002831213488622

White, K. (2006). Self-selected sample. In K. White, The Sage Dictionary of Health and Society (p. 188). London: Sage. https://doi.org/10.4135/97814462 15159

Woll, H. (2013). Process diary as methodological approach in longitudinal phenomenological research. Indo-Pacific Journal of Phenomenology, 13(2), 1-11. https://doi.org/10.2989/IPJP.2013.13. 2.2.1176A

Wolmarans, N., Smit, R., Collier-Reed, B., \& Leather, H. (2010). Addressing concerns with the NSC: An analysis of first-year student performance in Mathematics and Physics. In V. Mudaly (Ed.), Proceedings of the 18th Annual Meeting of the Southern African Association for Research in Mathematics, Science and Technology Education (pp. 274-284). KwaZulu-Natal.

Yi, J.-Y. (2008). The use of diaries as a qualitative research method to investigate teachers' perception and use of rating schemes. Journal of Pan-Pacific Association of Applied Linguistics, 12(1), 1-10.

Y1lmazer, Z., \& Keklikci, H. (2015). The effects of teaching geometry on the academic achievement by using puppet method. Procedia-Social and Behavioral Sciences, 191, 2355-2358. https://doi.org/10.1016/ j.sbspro.2015.04.463

\section{http://www.ejmste.com}

